D) Check for updates

Cite this: Food Funct., 2020, 11, 3227

\section{Extracts from Vaccinium myrtillus L. fruits as a source of natural colorants: chemical characterization and incorporation in yogurts}

\author{
Tânia C. S. P. Pires, ${ }^{a, b}$ Maria Inês Dias, ${ }^{a}$ Márcio Carocho, ${ }^{a}$ João C. M. Barreira, (D) a \\ Celestino Santos-Buelga, (D) ${ }^{b}$ Lillian Barros (D) ${ }^{a}$ and Isabel C. F. R. Ferreira (D) *a
}

Received 5th December 2019, Accepted 6th March 2020

DOI: $10.1039 /$ c9fo02890k

rsc.li/food-function

\begin{abstract}
The food industry is always seeking innovative approaches to maintain consumers' interest and increase their awareness towards the healthiness of diets. Therefore, much interest has been given to natural food additives, namely colourants. In this work, a bilberry extract was primarily characterized in terms of anthocyanin compounds by UPLC-DAD-ESI/MSn, and its colouring capacity was further compared with a synthetic anthocyanin colourant (E163) in different yogurt formulations. The prepared samples were evaluated in different periods ( 0 and 7 days) for nutritional profile, individual fatty acids, soluble sugars and external colour to determine the effects of each additive. Overall, the major anthocyanin compounds in bilberry were malvidin glycoside and delphinidin glycoside derivatives. With regard to the prepared yogurts, all samples maintained the nutritional profile, individual fatty acids and soluble sugars, independent of storage time. Nonetheless, bilberry extracts showed lower colouring capacity when compared to that of E163, despite the higher stability of bilberry extract throughout the storage time, when compared to that of E163. Furthermore, another advantage of this natural extract is that it has potential bioactive properties that can be conferred to foods, due to their high content of bioactive compounds, such as anthocyanins.
\end{abstract}

\section{Introduction}

Colour is an important sensory attribute of foods that often plays an important role in the success of a product, namely as a quality indicator of flavour, safety, nutritional value, and other parameters. ${ }^{1}$ Beyond conferring colours, food colourants are also used to overcome colour variation in foods and other related imperfections. The popularity of artificial colourants is associated with their low production cost, high resistance and chemical stability ${ }^{1}$ but natural colourants are generally considered healthier than their synthetic counterparts, since most of them are derived from edible plants or fruits. ${ }^{2}$ There are reports that link hyperactivity and allergies in children with exposure to artificial colourants, a fact that has stimulated the scientific community to search for new and improved natural extracts, which can be used as natural pigments and colourants. $^{2}$

\footnotetext{
${ }^{a}$ Centro de Investigação de Montanha (CIMO), Instituto Politécnico de Bragança, Campus de Santa Apolónia, 5300-253 Bragança, Portugal. E-mail: iferreira@ipb.pt; Fax: +351 273 325405; Tel: +351273303219

${ }^{b}$ Grupo de Investigación en Polifenoles (GIP-USAL), Facultad de Farmacia, Universidad de Salamanca, Campus Miguel de Unamuno s/n, 37007 Salamanca, España
}

Flavonoids are a group of secondary plant metabolites characterized by a $\mathrm{C}_{6} \mathrm{C}_{3} \mathrm{C}_{6}$ carbon backbone. Among these phytochemical compounds, anthocyanins are an important subclass of water-soluble pigments responsible for the colouration from blue to orange in plants. ${ }^{3}$ Vaccinium myrtillus L., also known as bilberry, is one of the natural sources of this group of compounds. Besides being responsible for the bluish-red colour of the bilberry fruit, anthocyanins are also related to many health benefits, including cardioprotective, anti-inflammatory, antimicrobial, antioxidant, and hypoglycaemic effects, thus being of great interest to the food industry. ${ }^{4}$ In bilberry fruits, the major anthocyanins are represented by C-3-O-glucosides, $O$-galactosides, and $O$-arabinosides of cyanidin, delphinidin, petunidin, peonidin, and malvidin. ${ }^{5}$

The market of functional foods and ingredients has increased paired with consumer awareness about the importance of healthy eating and lifestyle. The concern about the substitution of artificial colourants with natural counterparts is growing. There are several studies that prove the effectiveness of incorporating anthocyanins as natural pigments into various food matrices, with satisfactory results in terms of stability. ${ }^{6}$ The European Food Safety Authority (EFSA) allows the use of anthocyanins extracted from fruits in various types of foods, namely dairy products, cereals and others, under the 
number E163. ${ }^{7}$ The fruit sources used to produce E-163 are not detailed in the commission regulation 231/2012, the common sources being grape skins, blackcurrant, black carrot, or purple sweet potato. Bilberry fruits are not a common source for E163, but, given their high abundance (77000 ha worldwide in 2010), they could constitute an alternative source. ${ }^{8}$

Yogurts are one of the most consumed dairy products throughout the world due to their organoleptic and nutritional value. These lactic foods could benefit from colourings derived from natural compounds by appealing to the growing healthrelated awareness among consumers. ${ }^{9}$ However, one of the drawbacks of using anthocyanins and other natural colourants is their instability, having a tendency to change hue and lose colour intensity after a few hours or days, highlighting the importance of stability studies. Herein, bilberry's anthocyanins have been used to colour yogurts, which were further compared in terms of stability (7 days) with a commercial anthocyanin (E163) extract from CHR Hansen.

\section{Materials and methods}

\subsection{Sample preparation}

Dried samples of fruits of Vaccinium myrtillus L. (bilberry) were provided by RBRfoods (Castro D'aire, Portugal). After reception, samples were reduced to a fine dried powder, using a domestic grinder ( 20 mesh; model A327R1, Moulinex, Spain) and mixed to obtain homogenous samples.

\subsection{Bilberry extract preparation and compound identification by LC-DAD-ESI/MS}

To prepare the extracts, $1 \mathrm{~g}$ of each sample was extracted by maceration with $30 \mathrm{~mL}$ of distilled water $\left(25^{\circ} \mathrm{C}, 150 \mathrm{rpm}\right.$, $1 \mathrm{~h}$ ), followed by filtration through a Whatman filter paper no. 4. Afterwards, the residue was extracted with one additional portion of water $(30 \mathrm{~mL})$ and the pooled extracts were evaporated under reduced pressure (rotary evaporator Büchi R-210, Flawil, Switzerland), frozen and lyophilized. ${ }^{10}$

The lyophilized extract was then re-dissolved in ethanol/ water $(80: 20 \mathrm{v} / \mathrm{v})$ at $5 \mathrm{mg} \mathrm{mL}^{-1}$, for phenolic profile evaluation, using a Dionex Ultimate 3000 UPLC (Thermo Scientific, San Jose, CA, USA), linked to a diode array detector (preferential wavelength of $520 \mathrm{~nm}$ ) and to a mass spectrometer Linear Ion Trap LTQ XL (Thermo-Finnigan, San Jose, CA, USA) working in positive mode. ${ }^{11}$ Anthocyanins were identified based on their retention, absorption spectra and mass characteristics in comparison with commercial standards when available and our library data. Calibration curves of available phenolic standards (Polyphenols, Sandnes, Norway) were constructed from the areas of the peaks recorded at $520 \mathrm{~nm}$ to perform quantitative analysis: cyanidin-3-O-glucoside $\left(y=630276 x-153.83, R^{2}=\right.$ 0.999); delphinidin-3-O-glucoside $\left(y=557274 x+126.24, R^{2}=\right.$ 0.999); malvidin-3-O-glucoside $\left(y=477014.9 x+38.376, R^{2}=\right.$ $0.999)$; and peonidin 3-O-glucoside $\left(y=537017 x-71.469, R^{2}=\right.$ 0.999). The compounds were quantified via the calibration curve of the most similar available standard. The results were expressed as $\mathrm{mg} \mathrm{g}^{-1}$ of dry extract.

\subsection{Fortification of yogurts with the natural and commercial colorant additive}

2.3.1 Incorporation process. Natural yogurts (no colour) were acquired at a local market (Bio Natural brand) and had a labelled nutritional composition (per $100 \mathrm{~g}$ ) of $3.8 \mathrm{~g}$ of fat, $5 \mathrm{~g}$ of protein and $4.7 \mathrm{~g}$ of carbohydrates, which corresponded to $73 \mathrm{kcal}$. Yogurts were then divided into three groups with three samples (70 g each) per group. Group A consisted of the plain yogurt group, without any incorporation, while group B was incorporated with $0.02 \%$ of E163 (0.014 g; CHR Hansen, Denmark, prepared from grapes from the Mediterranean region), and group $\mathrm{C}$ was incorporated with $0.42 \%$ of bilberry extract $(0.294 \mathrm{~g})$. All samples were stored for 7 days $\left(5^{\circ} \mathrm{C}\right)$ and the analysis was conducted on day 0 and day 7 to evaluate their stability.

\subsection{Nutritional and chemical composition}

2.4.1 Nutritional composition. The proximate composition was analysed according to AOAC procedures, ${ }^{12}$ including protein (991.02), crude fat (989.05) and ash (935.42) contents. The Kjeldahl method was used for crude protein $(N \times 6.25)$; incineration at $600 \pm 15{ }^{\circ} \mathrm{C}$ for 5 hours was used for ash content, while crude fat was determined using a Soxhlet apparatus with petroleum ether as the recycling solvent; total carbohydrates were calculated by difference. The total energy was calculated using the following equation: energy (kcal) $=4 \times(\mathrm{g}$ protein $+\mathrm{g}$ carbohydrates $)+9 \times(\mathrm{g}$ fat $)$.

2.4.2. Chemical composition. Soluble sugars and individual fatty acids were analysed using HPLC and GC, respectively. Free sugars were determined by HPLC coupled to a refraction index detector (HPLC-RI; Knauer, Smartline system 1000, Berlin, Germany), using melezitose as the internal standard. ${ }^{13,14}$

The fatty acids were determined by gas chromatography coupled with a flame ionization detector (GC-FID/capillary column, DANI model GC 1000, Contone, Switzerland), using a split/splitless injector and a Macherey-Nagel column. The identification of fatty acids was performed by comparing the relative retention times of the fatty acid methyl esters (FAME) peaks from the samples with commercial standards. ${ }^{13,14}$

\subsection{External colour}

External colour was analyzed using a portable colorimeter CR400 (Konica Minolta, Chiyoda, Tokyo, Japan) using the C65 illuminant, which represents the midday light in Europe, and a standard from the International Commission of Illumination (CIE). The CIE $L^{*}, a^{*}$, and $b^{*}$ colour space coordinates were used, where $L^{*}$ represents lightness, $a^{*}$ represents redness (red-green), and $b^{*}$ represents yellowness (yellow-blue), with a $10^{\circ}$ observer angle and $8 \mathrm{~mm}$ aperture. The variation in total color difference $\left(\Delta E^{*}\right)$ between yogurt samples was calculated using the following equation:

$$
\Delta E^{*}=\sqrt{\left(L_{2}^{*}-L_{1}^{*}\right)^{2}+\left(a_{2}^{*}-a_{1}^{*}\right)^{2}+\left(b_{2}^{*}-b_{1}^{*}\right)^{2}}
$$

\subsection{Statistical analysis}

Throughout the manuscript, all data are expressed as mean \pm standard deviation. Samples were analyzed by a two-way 
ANOVA with type III sums of squares using the SPSS Software, version 25. This multivariate general linear model evaluates the effect of each individual factor, storage time (ST) and incorporation type (IT), independent of each other. If a significant interaction $(<0.05)$ among the two factors $(\mathrm{ST} \times \mathrm{IT})$ occurred, these were evaluated simultaneously, and any possible general conclusions or tendency had to be inferred from the estimated marginal means (EMM). If there was no significant interaction $(>0.05)$, each factor was evaluated independently using a simple Student's $T$ test (for ST) or a Tukey's multiple comparison test (IT) when the means were homoscedastic, and a Tamhane's T2 for heteroscedastic samples. Homoscedasticity was evaluated using Levene's test.

Additionally, principal components analysis (PCA) was applied to evaluate the affinity (correlation) of each studied variable (nutritional parameters, individual compounds, color parameters and $\mathrm{pH}$ ) with different mathematical functions (principal components). The number of dimensions kept for data analysis was assessed by the respective eigenvalues (which should be greater than one), by the Cronbach's alpha value (which must be positive) and also by the total percentage of variance (which should be the highest possible) explained by the selected components. Principal components were plotted considering different incorporation types (IT).

All analyses were carried out using a significance level of 0.05 .

\section{Results and discussion}

The phenolic profile of bilberry extract was characterized to identify compounds associated with its bioactivity and colouring potential. Then, the colouring capacity of the extract was tested by incorporation in yogurts and compared with a plain yogurt formulation (without any colourant) and with a positive control, namely E163 which is an industrially produced colourant.

\subsection{Identification and quantification of phenolic compounds in bilberry extract}

Due to the prevailing colouring capacity of anthocyanins, these compounds were thoroughly characterized in the extract obtained from bilberry fruit. Eleven anthocyanin glycosides were detected derived from delphinidin (Dp; peaks 1, 2 and 4), cyanidin (Cy; peaks 3 and 6), petunidin (Pt; peaks 5 and 8), peonidin (Pn; peaks 7 and 10), and malvidin (Mv; peaks 9 and 11). Compounds were identified based on their chromatographic behaviour and absorption and mass spectra (Table 1). Peaks presented $\mathrm{MS}^{2}$ fragments corresponding to distinct losses of hexosyl $(-162 \mathrm{u})$ and pentosyl $(-132 \mathrm{u})$ moieties, with elution orders coherent with the expected polarity of the sugar substituents. The position and nature of the sugar moieties were assigned taking into account the previously described literature regarding bilberry extracts, ${ }^{5-17}$ as well as by comparison with available commercial standards and data from our compound library.

The Mv glycosides, especially malvidin-3-O-galactoside and malvidin-3-O-arabinoside, were the main compounds present, comprising $48 \%$ of the total anthocyanin content, whereas Dp derivatives (Dp-galactoside, Dp-glucoside and Dp-arabinoside) represented 22\%, and Pt 20\% (Pt-galactoside and Ptarabinoside).

\subsection{Nutritional profile}

The main objective of analysing the nutritional profile was to verify if any change took place along the seven days of storage at $5{ }^{\circ} \mathrm{C}$ in the different yogurt formulations. Since two different factors contributed to the result variability, a 2-way ANOVA was used, allowing us to evaluate the effect of each factor, independent of the others. Table 2 shows the nutritional profile of each yogurt formulation (plain, E163, and bilberry extract) in the lower section, and the two analysed times ( 0 and 7 days) in the upper section. The nutrient values indicated in each part of the table correspond respectively to the means of each storage time (ST) including the three incorporation types (IT),

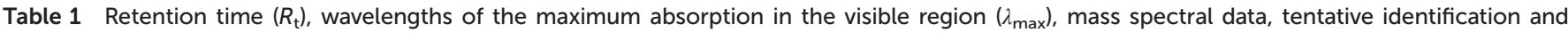
quantification ( $\mathrm{mg} \mathrm{g}^{-1}$ of extract) of the anthocyanins present in the hydromethanolic extracts of bilberry fruits

\begin{tabular}{|c|c|c|c|c|c|c|}
\hline Peak & $R_{\mathrm{t}}(\min )$ & $\lambda_{\max }(\mathrm{nm})$ & {$[\mathbf{M}]^{+}(m / z)$} & $\mathrm{MS}^{2}(m / z)$ & Tentative identification & $\begin{array}{l}\text { Quantification } \\
\left(\mathrm{mg} \mathrm{g}^{-1} \text { of extract) }\right.\end{array}$ \\
\hline 1 & 14.4 & 524 & 465 & $303(100)$ & Delphinidin-3-O-galactoside ${ }^{a}$ & $2.65 \pm 0.01$ \\
\hline 2 & 15.9 & 526 & 465 & $303(100)$ & Delphinidin-3-O-glucoside ${ }^{a}$ & $0.162 \pm 0.001$ \\
\hline 3 & 16.9 & 518 & 449 & $287(100)$ & Cyanidin-3-O-galactoside ${ }^{b}$ & $0.62 \pm 0.02$ \\
\hline 4 & 17.7 & 524 & 435 & $303(100)$ & Delphinidin-3-O-arabinoside ${ }^{a}$ & $1.91 \pm 0.02$ \\
\hline 5 & 19.2 & 528 & 479 & $317(100)$ & Petunidin-3-O-galactoside ${ }^{c}$ & $2.50 \pm 0.02$ \\
\hline 6 & 20.2 & 514 & 419 & $287(100)$ & Cyanidin-3-O-arabinoside ${ }^{b}$ & $0.464 \pm 0.004$ \\
\hline 7 & 21.7 & 518 & 463 & $301(100)$ & Peonidin-3-O-galactoside ${ }^{d}$ & $0.45 \pm 0.01$ \\
\hline 8 & 22.6 & 516 & 449 & $317(100)$ & Petunidin-3-O-arabinoside ${ }^{c}$ & $1.67 \pm 0.03$ \\
\hline 9 & 22.8 & 528 & 493 & $331(100)$ & Malvidin-3-O-galactoside ${ }^{c}$ & $5.64 \pm 0.05$ \\
\hline 10 & 26.1 & 522 & 433 & $301(100)$ & Peonidin-3-O-arabinoside ${ }^{d}$ & $0.550 \pm 0.004$ \\
\hline \multirow[t]{2}{*}{11} & 28.9 & 528 & 463 & $331(100)$ & Malvidin-3-O-arabinoside ${ }^{c}$ & $4.45 \pm 0.02$ \\
\hline & & & & & Total anthocyanins & $21.1 \pm 0.2$ \\
\hline
\end{tabular}

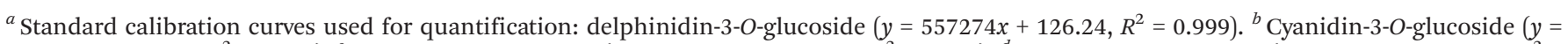

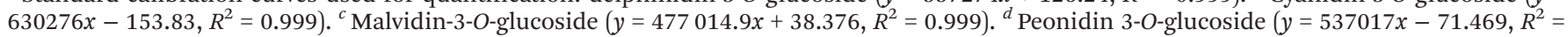
$0.999)$. 
Table 2 Nutritional profile of the yogurt samples as a function of the added colorant and the storage time expressed in $\mathrm{g}$ per $100 \mathrm{~g}$ of fresh weight, and energy in kcal per $100 \mathrm{~g}$ of fresh weight

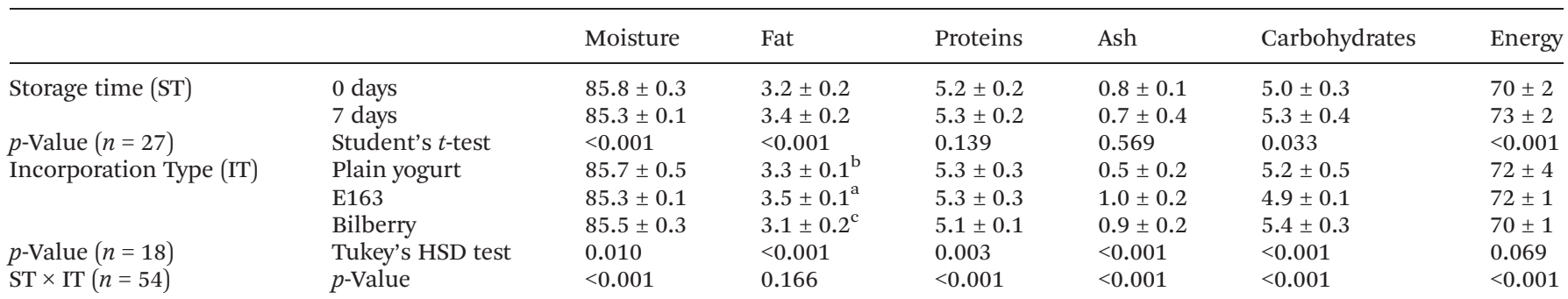

In each row and within each storage period, different letters mean significant statistical differences between plain yogurts, yogurts incorporated with E163 and yogurts incorporated with bilberry extract $(p<0.05)$.

and vice versa, therefore the standard deviation values should not be regarded as accuracy measure. Besides the effect of each individual factor, the significance of their interaction (ST $\times$ IT) was also evaluated. If a significant interaction was found, the classification obtained for multiple comparisons could not be observed, since the effect of each factor was not equal for all levels of the other. In those cases, the presented general tendencies were obtained from the Estimated Marginal Means (EMM) plots. Inversely, if no interaction was found $(p>0.050)$, the factor was classified individually using either Tukey's or Tamhane T2 tests (depending on the homoscedasticity of the distribution), for IT, and a Student's $t$-test for ST.

Yogurts presented a moisture content above $85 \mathrm{~g}$ per $100 \mathrm{~g}$ and approximately the same levels ( $\sim 5 \mathrm{~g}$ per $100 \mathrm{~g})$ of proteins and carbohydrates, with slightly lower ( 3.3 g per $100 \mathrm{~g})$ fat content, corresponding to energy values around $70 \mathrm{kcal}$ per $100 \mathrm{~g}$, validating the labelled information, and showing to be consistent with the typical nutritional composition of plain yogurt ${ }^{18}$ ST and IT did not show to exert a cooperative effect over fat content, which was significantly higher in yogurts containing E163 and in stored samples. In turn, the interaction among factors $(\mathrm{ST} \times \mathrm{IT})$ was significant $(p<0.050)$ for all other parameters in Table 2. Nonetheless, some conclusions could be obtained from the estimated marginal means corresponding to the combined results of these parameters, particularly the higher energy values in samples at 7 days $(73 \pm$ 2 kcalper $100 \mathrm{~g} \mathrm{fw}$ ), as it seems logical owing to the moisture loss during storage. Curiously, the ash content is significantly higher in yogurts containing E163 $(1.0 \pm 0.2 \mathrm{~g}$ per $100 \mathrm{~g}$ fw $)$ and the bilberry extract, indicating that minerals were incorporated as a part of the composition of those additives. Despite the mathematical significance of these differences, all yogurt samples showed very slight nutritional differences. This fact should be expected as food additives are added to food for a technological goal and should not change in any way the nutritional and chemical aspects of food, except for the cases it is intended for.

\subsection{Individual compound analysis}

In terms of individual compounds (Table 3 ) the fatty acids present in the highest percentages were palmitic acid: C16:0 ( $\sim 35 \%)$, oleic acid: C18:1n9 ( 21\%), myristic acid: C14:0 $(\sim 12 \%)$, and stearic acid: C18:0 ( 11\%), which is agreement with the results reported in a similar work. ${ }^{18}$ As expected, lactose constitutes the main sugar. In line with the results obtained in the nutritional analysis, the differences obtained for each of the studied individual compounds reflected the significant interaction of both factors (ST and IT), except for the case of lactose, which showed statistically higher contents (despite low magnitude) in yogurts added with bilberry. Accordingly, the few overall tendencies had to be obtained from the EMM plots, which indicated lower C18:0 percentages and galactose contents in plain yogurts.

Table 3 Individual fatty acids found in the yogurt samples as a function of the added colorant and the storage time, expressed as relative percentages of themselves

\begin{tabular}{|c|c|c|c|c|c|c|c|c|c|c|}
\hline & & C14:0 & C16:0 & C18:0 & C18:1n9 & SFA & MUFA & PUFA & Galactose & Lactose \\
\hline & $7 \mathrm{da}$ & $12.2 \pm 0.2$ & $35.8 \pm 0.2$ & $11.3 \pm 0.1$ & $20 \pm 1$ & $73 \pm 1$ & $23 \pm 1$ & $4.8 \pm 0.2$ & $0.6 \pm 0.1$ & $4.1 \pm 0.3$ \\
\hline & E163 & $12.0 \pm 0.3$ & $35.2 \pm 0.5$ & $11.3 \pm 0.1$ & $21 \pm 1$ & $72 \pm 1$ & $23 \pm 1$ & $5.2 \pm 0.5$ & $0.7 \pm 0.1$ & $4.0 \pm 0.1^{\mathrm{b}}$ \\
\hline & Bilberry & $12.5 \pm 0.5$ & $35.8 \pm 0.4$ & $11.6 \pm 0.3$ & $20 \pm 1$ & $73 \pm 1$ & $23 \pm 1$ & $4.1 \pm 0.4$ & $0.6 \pm 0.1$ & $4.4 \pm 0.3^{\mathrm{a}}$ \\
\hline$p$-Value $(n=18)$ & Tukey's HSD test & $<0.001$ & 0.004 & $<0.001$ & 0.240 & 0.119 & 0.244 & $<0.001$ & $<0.001$ & $<0.001$ \\
\hline
\end{tabular}

In each row and within each storage period, different letters mean significant statistical differences between plain yogurts, yogurts incorporated with E163 and yogurts incorporated with bilberry extract $(p<0.05)$. 


\subsection{External colour and $\mathrm{pH}$}

Owing to the incorporation of the colouring materials, the main differences were expected to be observed for colour parameters. Besides the Cartesian coordinates $\left(L^{*}, a^{*}\right.$ and $\left.b^{*}\right)$, the cylindrical coordinates $\left(C^{*}\right.$ and $h$ ) were also obtained; $C^{*}$, which stands for chroma (relative to saturation), was calculated as $\sqrt{a^{* 2}+b^{* 2}}$, while the formula used to calculate the hue angle $(h)$ depended on the values of $a^{*}$ and $b^{*}$, e.g. , if $a^{*}$ and $b^{*}$ were negative, the formula was $180+\left(\arctan \frac{\frac{b^{*}}{a^{*}}}{2 \pi}\right) \times 360$.

As depicted in Table 4, all parameters showed significant differences among different yogurt formulations, while the storage time had a very low effect, but for $L^{*}$ values, which were slightly lower in samples at day 0. Despite the significant effect of IT, the statistical classification results could not be presented, since the interaction among factors was statistically significant in all cases. Nonetheless, the EMM plots allowed concluding that $L^{*}, b^{*}$, and $C^{*}$ were higher in plain yogurt samples, which in turn showed lower $h^{*}$ and, in particular, $a^{*}$ values, as it is logical taking into account due to the very low quantity of red colour existing in the samples without the colorants. A visual representation of the yogurt colour is shown in Fig. 1, where it is clear that both colorants provided colour to the yogurts, although there was a lower colour intensity for the E163 yogurts, particularly at day 7 and mostly due to a decrease in the values of the $a^{*}$ component (Fig. 2). This is corroborated by the calculated $\Delta E$ (total colour difference), which after 7 days reached a value of 3.86 for the E163 yogurts compared to day 0, while the difference for bilberry coloured yogurts was 0.91 , very similar to the plain yogurt sample variation of 0.73 . This proves the higher stability of the bilberry extract and its viability as a food colourant for yogurt. Similar results of enhanced stability of colorants from natural sources were reported by Nontasan et $a l .{ }^{19}$ who found stable $L^{*}$ and $C^{*}$ values in yogurts added with black rice bran for 21 days under $4{ }^{\circ} \mathrm{C}$ storage, and by Mohammadi-Gouraji et al. ${ }^{20}$ following the addition of phycocyanin extracted from Spirulina platensis under similar storage conditions. This trend of incorporation of natural colourants in yogurts, not only with pigments from fruits but also flowers and other plant parts, seems to have gained traction, having good consumer acceptance due to a higher correlation in the colour-flavor perception..$^{20-22}$

The $\mathrm{pH}$ values for each IT were statistically different, with yogurts containing E163 presenting less acidic values. On the other hand, ST had no effect at all on $\mathrm{pH}$ values, independent of IT.

Table 4 External colour profile of the yogurts as a function of the added colorant and along the storage time expressed as $L^{*}, a^{*}, b^{*}, C^{*}$ and $h$, as well as $\mathrm{pH}$

\begin{tabular}{|c|c|c|c|c|c|c|c|}
\hline & & $L^{*}$ & $a^{*}$ & $b^{*}$ & $C^{*}$ & $h$ & $\mathrm{pH}$ \\
\hline & 7 days & $91 \pm 2$ & $0 \pm 2$ & $8 \pm 1$ & $8 \pm 1$ & $208 \pm 70$ & $4.6 \pm 0.2$ \\
\hline \multirow{2}{*}{ Incorporation Type (IT) } & E163 & $89 \pm 1$ & $3.1 \pm 0.5$ & $6.4 \pm 0.5$ & $7.3 \pm 0.3$ & $244 \pm 12$ & $4.9 \pm 0.1^{\mathrm{a}}$ \\
\hline & Bilberry & $88 \pm 1$ & $1.5 \pm 0.3$ & $6.2 \pm 0.5$ & $6.4 \pm 0.5$ & $256 \pm 2$ & $4.6 \pm 0.1^{\mathrm{b}}$ \\
\hline$p$-Value $(n=18)$ & Tukey's HSD test & $<0.001$ & $<0.001$ & $<0.001$ & $<0.001$ & $<0.001$ & $<0.001$ \\
\hline
\end{tabular}

In each row and within each storage period, different letters mean significant statistical differences between plain yogurts, yogurts incorporated with E163 and yogurts incorporated with bilberry extract $(p<0.05)$.

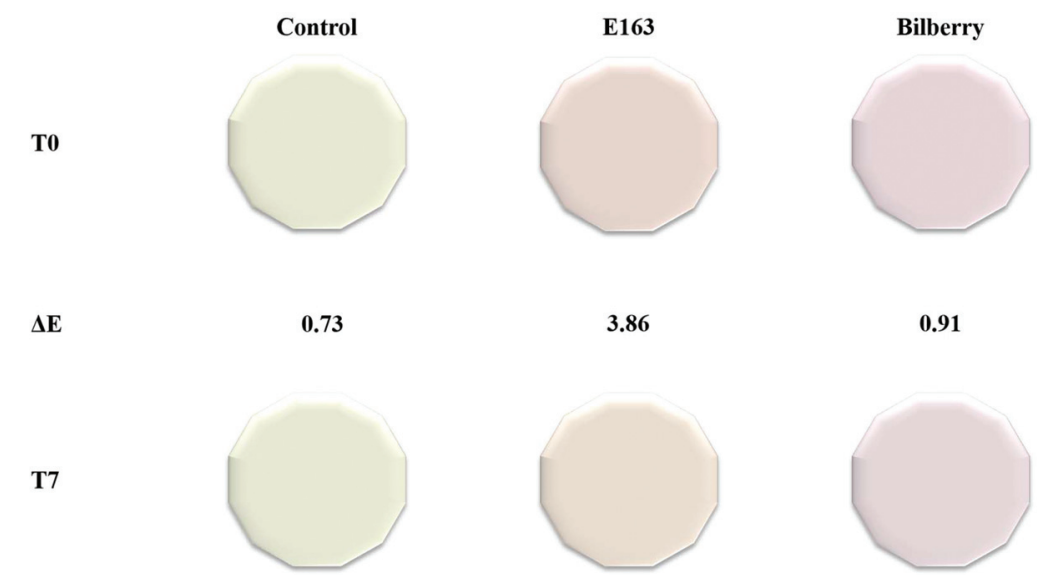

Fig. 1 Variation of the yogurt colours during the storage time. 


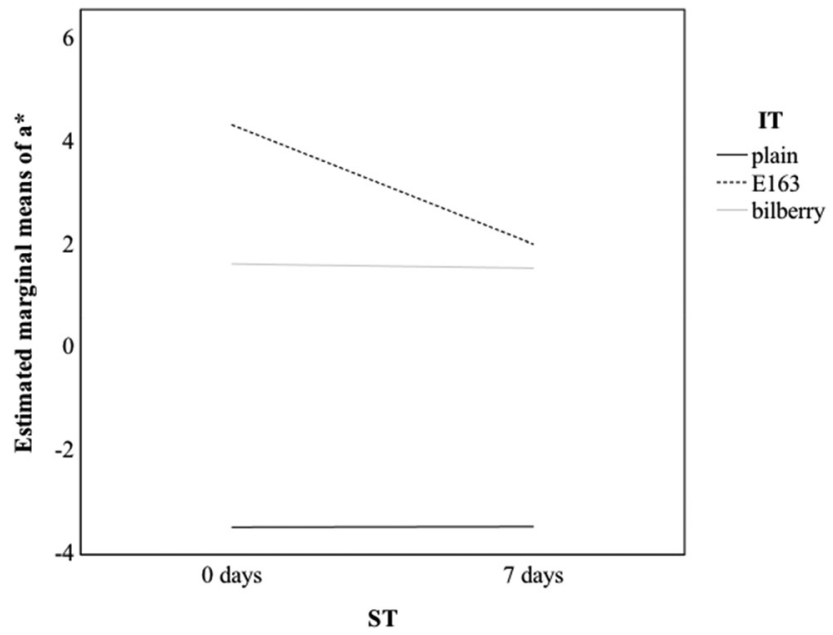

Fig. 2 Estimated marginal mean plots of $a^{*}$ in yogurt formulations along the storage time.

\subsection{Principal component analysis}

This analysis was performed to verify the variables with the highest differences among each assayed IT. The first two defined dimensions (first: Cronbach's $\alpha=0.920$, eigenvalue $=$
8.232, explained variance $=47.4 \%$; second: Cronbach's $\alpha=$ 0.871 , eigenvalue $=5.940$, explained variance $=37.0 \%$ ) are plotted in Fig. 3. As can be observed, three main groups were formed, two distinct groups corresponding to plain yogurt markers and a big third group containing markers corresponding to yogurts added with E163 or added with bilberry extracts. In an initial analytical approach, it is easy to observe that markers corresponding to plain yogurts and those added with E163 or bilberry extracts were basically separated by dimension 1; considering the variable placement, it is also straightforward that color parameters were the ones with the highest contribution for this separation. Specifically, plain yogurts were mainly characterized by their high $L^{*}, b^{*}$ and $C^{*}$ values, while yogurts containing coloring agents present high $a^{*}$ and $h^{*}$ as the most distinguishable features.

In turn, the second dimension separated two distinct groups of markers, both belonging to plain yogurts. According to the SPSS output these two groups correspond exactly to the two assayed periods: 0 days and seven days, which indicates that these types of yogurts did not maintain their characteristics throughout the storage time. The bottom left group includes the 0 days markers (characteristically containing high moisture, C18:1n9 and MUFA contents), while the upper left group contains the markers corresponding to

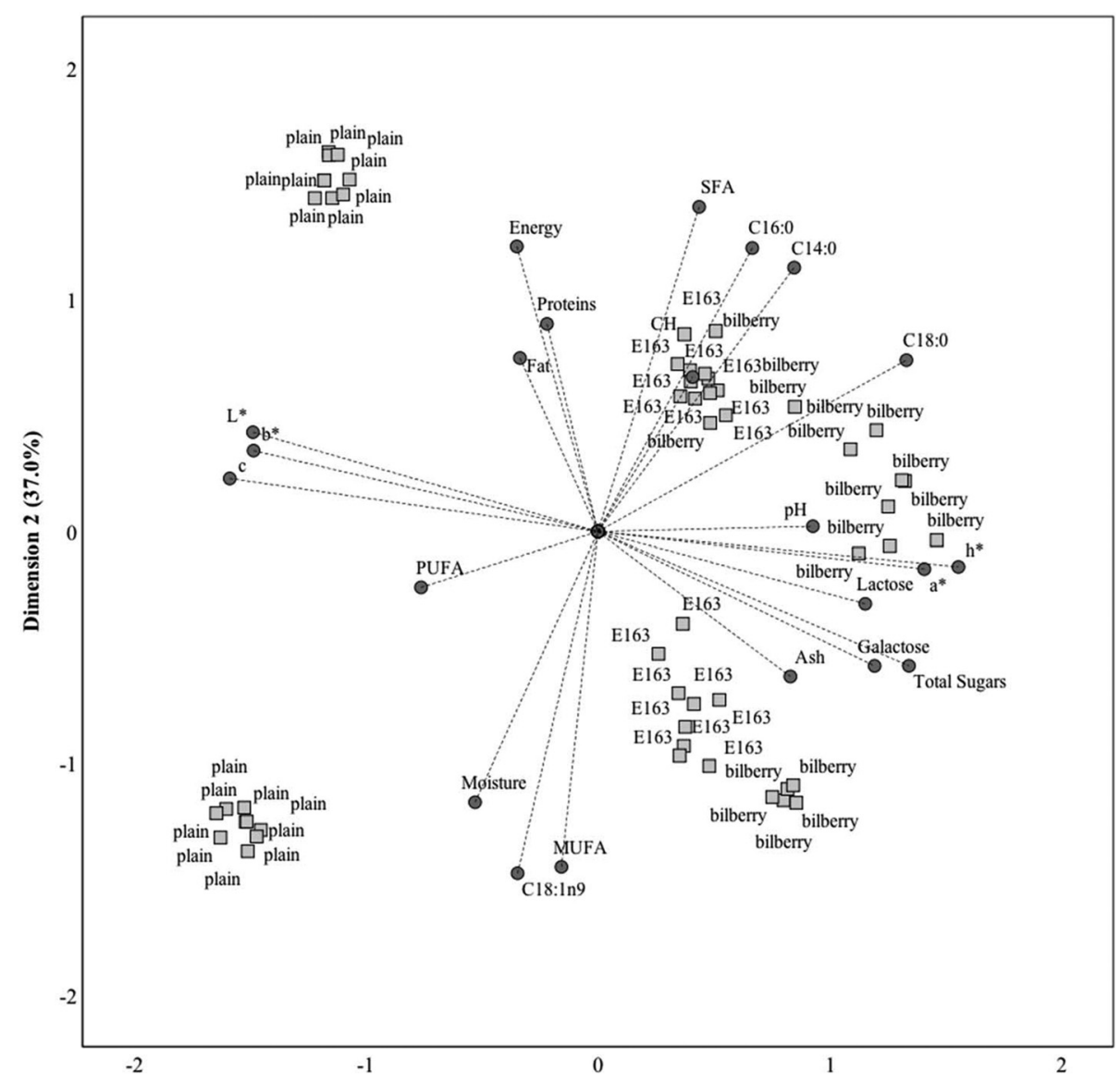

Fig. 3 Canonical discriminant function coefficients defined from the evaluated parameters and plotted to highlight differences among incorporation types. 
plain yogurts stored for 7 days (high fat, protein and energy contents).

Nonetheless, with regard to the yogurts with E163 or bilberry extracts, there was no separation among non-stored and stored samples, which is solid evidence of the stability provided by both additives. Despite the resemblance among yogurts with E163 or bilberry extract, the markers corresponding to this last IT were generally placed on the right of those with E163, which is an overall indicator of a higher coloring effectiveness in the case of bilberry extracts (closest location to the $a^{*}$ variable).

\section{Conclusions}

Bilberry, when used as a natural colorant for yogurts, showed very interesting potential not only as a stable colourant, but also as a functionalizing agent for this lactic product; moreover, it shows higher stability than its commercial counterpart E163 (counting grape anthocyanins). Likewise, the anthocyanin level of this berry might present additional health benefits to the consumers of products functionalized with its extracts.

\section{Conflicts of interest}

The authors declare that they have no conflicts of interest regarding this manuscript.

\section{Acknowledgements}

The authors are grateful to the Foundation for Science and Technology (FCT, Portugal) for financial support through national funds FCT/MCTES to CIMO (UIDB/00690/2020) and T. C.S.P. Pires (SFRH/BD/129551/2017) grant. National funding by FCT, P.I., through the institutional scientific employment program-contract for M.I. Dias and L. Barros contracts, and through the individual scientific employment program-contract for J. Barreira contract. This work is funded by the European Structural and Investment Funds (FEEI) through the Regional Operational Program North 2020, within the scope of Project NORTE-01-0145-FEDER-023289: DeCodE and project Mobilizador ValorNatural ${ }^{\circ}$. M. Carocho also thanks the project ValorNatural for his research contract. The authors are also grateful to FEDER-Interreg España-Portugal programme for financial support through the project 0377_Iberphenol_6_E. The GIP-USAL is financially supported by the Spanish Government through the project AGL201564522-C2-2-R.

\section{References}

1 G. Sigurdson, P. Tang and M. Giusti, Natural Colorants: Food Colorants from Natural Sources, Food Sci. Technol., 2015, 8, 261-280.
2 M. Pop, A. X. Lupea, S. Popa and C. Gruescu, Colour of Bilberry (Vaccinium Myrtillus Fruits) Extracts, Int. J. Food Prop., 2010, 13, 771-777.

3 M. Carocho and I. C. F. R. Ferreira, The role of phenolic compounds in the fight against cancer - A review Anticancer, Agents Med. Chem., 2013, 13, 1236-1258.

4 R. Dinkova, P. Heffels, V. Shikov, F. Weber, A. Schieber and K. Mihalev, Effect of enzyme-assisted extraction on the chilled storage stability of bilberry (Vaccinium myrtillus L.) anthocyanins in skin extracts and freshly pressed juices, Food Res. Int., 2014, 65, 35-41.

5 D. Burdulis, V. Janulis, A. Milašius, V. Jakštas and L. Ivanauskas, Method Development for Determination of Anthocyanidin Content in Bilberry (Vaccinium myrtillus, L.) Fruits, J. Liq. Chromatogr. Relat. Technol., 2008, 31, 850-864.

6 V. T. Šaponjac, G. Ćetković, J. Čanadanović-Brunet, B. Pajin, S. Djilas, J. Petrović, I. Lončarević, S. Stajčić and J. Vulić, Sour cherry pomace extract encapsulated in whey and soy proteins: Incorporation in cookies, Food Chem., 2016, 207, 27-33.

7 E. F. S. A. (EFSA), Evaluation of anthocyanins (E 163) as a food additive, EFSA J., 2013, 11, 3145.

8 B. Strik, Organic blueberry production systems - Advances in research and industry, Acta Hortic., 2014, 1012, 257.

9 F. Arioui, D. Ait Saada and A. Cheriguene, Physicochemical and sensory quality of yogurt incorporated with pectin from peel of Citrus sinensis, Food Sci. Nutr., 2017, 5, 358364.

10 T. C. S. P. Pires, M. I. Dias, L. Barros, J. C. M. Barreira, C. Santos-Buelga and I. C. F. R. Ferreira, Incorporation of natural colorants obtained from edible flowers in yogurts, LWT - Food Sci. Technol., 2018, 97, 668-675.

11 G. A. Gonçalves, A. A. Soares, R. C. G. Correa, L. Barros, C. W. I. Haminiuk, R. M. Peralta, I. C. F. R. Ferreira and A. Bracht, Merlot grape pomace hydroalcoholic extract improves the oxidative and inflammatory states of rats with adjuvant-induced arthritis, J. Funct. Foods, 2017, 33, 408418.

12 AOAC, Official Methods of Analysis of AOAC International, AOAC International., 20th edn, 2016.

13 M. I. Dias, L. Barros, P. Morales, M. C. Sánchez-Mata, M. B. P. P. Oliveira and I. C. F. Ferreira, Nutritional parameters of infusions and decoctions obtained from Fragaria vesca L. roots and vegetative parts, LWT-Food Sci. Technol., 2015, 62, 32-38.

14 L. Barros, C. Pereira and I. C. F. R. Ferreira, Optimized Analysis of Organic Acids in Edible Mushrooms from Portugal by Ultra Fast Liquid Chromatography and Photodiode Array Detection, Food Anal. Methods, 2013, 6, 309-316.

15 N. Colak, A. K. Primetta, K. R. Riihinen, L. Jaakola, J. Grúz, M. Strnad, H. Torun and F. A. Ayaz, Phenolic compounds and antioxidant capacity in different-colored and non-pigmented berries of bilberry (Vaccinium myrtillus L.), Food Biosci., 2017, 20, 67-78. 
16 K. Aaby, S. Grimmer and L. Holtung, Extraction of phenolic compounds from bilberry (Vaccinium myrtillus L.) press residue: Effects on phenolic composition and cell proliferation, LWT - Food Sci. Technol., 2013, 54, 257-264.

17 J. Paes, R. Dotta, G. F. Barbero and J. Martínez, Extraction of phenolic compounds and anthocyanins from blueberry (Vaccinium myrtillus L.) residues using supercritical CO2 and pressurized liquids, J. Supercrit. Fluids, 2014, 95, 8-16.

18 C. P. Van Nieuwenhove, A. Moyano, P. Castro-Gómez, J. Fontecha, G. Sáez, G. Zárate and P. L. Pizarro, Comparative study of pomegranate and jacaranda seeds as functional components for the conjugated linolenic acid enrichment of yogurt, LWT - Food Sci. Technol., 2019, 111, 401-407.

19 S. Nontasan, A. Moongngarm and S. Deeseenthum, Application of Functional Colorant Prepared from Black Rice Bran in Yogurt, APCBEE Proc., 2012, 2, 62-67.
20 E. Mohammadi-Gouraji, S. Soleimanian-Zad and M. Ghiaci, Phycocyanin-enriched yogurt and its antibacterial and physicochemical properties during 21 days of storage, LWT - Food Sci. Technol., 2019, 102, 230236.

21 L. M. M. Gomes, N. Petito, V. G. Costa, D. Q. Falcão and K. G. De Lima Araújo, Inclusion complexes of red bell pepper pigments with $\beta$-cyclodextrin: Preparation, characterisation and application as natural colorant in yogurt, Food Chem., 2014, 148, 428-436.

22 D. D. G. C. Freitas-Sá, R. C. de Souza, M. C. P. de Araujo, R. G. Borguini, L. da S. de Mattos, S. Pacheco and R. L. de O. Godoy, Effect of jabuticaba (Myrciaria jaboticaba, (Vell) O. Berg) and jamelão (Syzygium cumini (L.) Skeels) peel powders as colorants on color-flavor congruence and acceptability of yogurts, LWT-Food Sci. Technol., 2018, 96, 215-221. 